\title{
TIChers - conscientização e formação de docentes da Educação Básica por mais mulheres na Computação
}

\author{
Sílvia Amélia Bim, Rita C. G. Berardi \\ Departamento Acadêmico de Informática - UTFPR - Curitiba, PR, Brasil \\ sabimeutfpr.edu.br, ritaberardi@utfpr.edu.br
}

\begin{abstract}
This article presents the TIChers project that carries out awareness and training actions for elementary, middle high and high school teachers to increase the representation of women in the Computing area. The strategy of working directly with teachers is still incipient in the Brazilian context. However, several studies indicate the influence of experiences in elementary, middle high and high school when choosing a professional career. The preliminary results are promising in the perspective of generating selfconfidence in teachers to address Computing issues with their classes.
\end{abstract}

Resumo. Este artigo apresenta o projeto TIChers que realiza ações de conscientização e formação de docentes da Educação Básica para aumentar a representatividade de mulheres na área de Computação. A estratégia de trabalhar diretamente com docentes ainda é incipiente no contexto brasileiro. Entretanto, vários estudos sinalizam a influência das experiências na Educação Básica na escolha de uma carreira profissional. Os resultados preliminares já se revelam promissores na perspectiva de gerar autoconfiança em docentes para abordar temas de Computação com suas turmas.

\section{Introdução}

A demanda por formação em Computação para docentes da Educação Básica ressurge e se torna urgente [Ribeiro 2019] a partir da inserção de competências relacionadas à tecnologia e computação na Base Nacional Comum Curricular - $\mathrm{BNCC}^{1}$. A Educação Infantil deverá cobrir conceitos de Cultura Digital e Letramento Digital, já o Ensino Fundamental I ( $1^{\circ}$ à $5^{\circ}$ série) abrange conceitos de Cultura Digital e Cidadania Digital e Ensino Fundamental II ( $6^{\circ}$ à $9^{\circ}$ série) abrange conceitos de Tecnologia e Sociedade e Pensamento Computacional. O desafio é que docentes destes níveis de educação deverão além de compreender também trabalhar em sala de aula com seus discentes sobre conteúdos antes inexistentes. Este projeto se justifica, dentre outras, por esta demanda específica e clara da Educação Básica.

Várias iniciativas estão buscando apoiar esta demanda como o próprio curso ${ }^{2}$ online disponibilizado pelo Ministério da Educação ou com o material divulgado pelo CIEB - Centro de Inovação para a Educação Brasileira ${ }^{3}$ porém, o desafio é dar o direcionamento adequado para o nível de conhecimento necessário e quais habilidades e competências devem ser de fato desenvolvidas. Habilidades que o Pensamento

\footnotetext{
${ }^{1} \mathrm{http}: / /$ basenacionalcomum.mec.gov.br/

${ }^{2} \mathrm{http} / / /$ avamec.mec.gov.br/\#/instituicao/seb/curso/3801/informacoes

${ }^{3} \mathrm{http}$ ://curriculo.cieb.net.br/curriculo
} 
Computacional deve desenvolver vão além de aprender uma linguagem de programação e devem englobar linguagem simples, não rebuscada e deve despertar o método de solução de problemas, como analisar problemas e resolvê-los. Muito mais que simplesmente construir algoritmos com uma linguagem específica, é conhecer o que é possível construir usando a computação como ferramenta.

Segundo Ivan Siqueira, criar a oportunidade para que o aprendizado do Pensamento Computacional aconteça já na Educação Básica pode trazer ganhos tanto para as pessoas (estudantes e docentes) quanto para a sociedade brasileira uma vez que a Computação é área estratégica para um projeto de país [Siqueira 2019].

Além da demanda para garantir acesso aos conceitos de Computação pelas pessoas envolvidas na Educação Básica (docentes e estudantes) também é urgente buscar soluções para o problema da baixa representatividade de mulheres na Computação. A computação multiplica somando. Por isto, cada elemento nesta soma é imprescindível para aumentar a representatividade das mulheres na Computação. É preciso somar esforços, somar pessoas, somar perfis, somar habilidades, somar responsabilidades, somar diferenças. Com todas essas somas é possível multiplicar o conhecimento sobre a computação que hoje encontra-se majoritariamente inerente ao contexto universitário. $\mathrm{O}$ conhecimento sobre a computação, sobre seu potencial, sobre suas necessidades ainda é pouco conhecido (ou até desconhecido) no contexto escolar, o que faz com que a própria área de estudo perceba uma defasagem por profissionais com diferentes perfis.

O objetivo do projeto TIChers é alcançar a capacidade de multiplicar o encanto pela área de Computação por meio do esclarecimento e desmistificação dos seus conceitos, a partir de ações com docentes da Educação Básica.

\section{Motivação}

A Sociedade Brasileira de Computação (SBC) através da Diretoria de Educação Básica vem participando das audiências públicas da BNCC para apresentar as Diretrizes para o Ensino de Computação na Educação Básica ${ }^{4}$. Embora o material apresentado seja bastante completo e detalhado a demanda por materiais que demonstrem como as diretrizes podem ser implementadas ainda é uma realidade. Desta forma, o Projeto TIChers busca responder a esta demanda.

Além desta perspectiva, a área de STEM - Science Technology Engineering and Mathematics tem buscado compreender o fenômeno da falta de diversidade de gênero nos cursos superiores e nas empresas. Especificamente na área de computação, a representatividade de mulheres é baixa, e por isto, algumas iniciativas têm sido desenvolvidas para mudar este cenário. No nível nacional atuante desde 2011, o Programa Meninas Digitais (PMD) chancelado pela SBC conta com diversos projetos parceiros espalhados pelo Brasil com o objetivo de despertar o interesse de meninas no final do ensino médio e ensino fundamental para a área de computação [Maciel et al. 2018].

O PMD realiza, através dos projetos parceiros, ações muito diversificadas: minicursos e oficinas de vários temas da Computação; realização de dinâmicas;

\footnotetext{
${ }^{4} \mathrm{http}: / /$ sbc.org.br/documentos-da-sbc/summary/203-educacao-basica/1220-bncc-em-itinerarioinformativo-computacao-2
} 
palestras com estudantes e profissionais que já atuam na área compartilhando suas experiências; realização de eventos etc ${ }^{5}$. O Projeto TIChres, como projeto parceiro, vem contribuir com a realização de oficinas para docentes da Educação Básica. Segundo [Graeff e Patias 2018] as famílias costumam reivindicar que as escolas auxiliem ativamente estudantes no processo de escolha profissional. Entretanto, a pesquisa de [Ribeiro 2020b] indica que o diálogo sobre a escolha profissional entre estudantes e docentes ainda é incipiente. Desta forma, espera-se que o TIChers trabalhe na conscientização e formação de docentes da Educação Básica sobre diversos conceitos da Computação para que possam multiplicar estes conhecimentos, incentivando a participação de mais mulheres na Computação.

$\mathrm{Na}$ experiência prévia das responsáveis pelo TIChers em um outro projeto parceiro do PMD constatou-se que as ações deveriam contemplar não somente estudantes, mas também docentes. A observação empírica durante as ações sinalizou que muitas meninas no ensino médio já haviam escolhido uma possível profissão mostrando que ações neste momento eram tardias para apresentar uma nova carreira como a computação. Além disso, também foi possível observar que docentes que acompanharam as atividades também precisavam de esclarecimentos sobre conceitos e sobre a própria carreira para que, de forma continuada, levarem para suas aulas o conhecimento iniciado durante as ações.

$\mathrm{O}$ fato determinante para a criação de um novo projeto parceiro do PMD foi o convite da Secretaria Municipal de Educação (SME) de Curitiba através do Departamento de Ensino Fundamental e da Coordenadoria de Tecnologias Digitais e Inovação. A demanda sinalizada pelo público alvo, direcionada especialmente para as coordenadoras do projeto TIChres, seguiu-se da afirmação "Acreditamos que oficinas ministradas por professoras podem criar mais empatia e autoconfiança nas professoras da Educação Básica." - representante da SME que fez o convite. Tal afirmação corrobora com os resultados de várias pesquisas que indicam a importância de role models para inspirar novos talentos para a Computação [Ribeiro 2020].

\section{Metodologia}

A metodologia do projeto segue a proposta de [Berardi et al 2019] que demonstra que um conteúdo com complexidade intermediária turmas de graduação pode ser trabalhado com meninas do ensino médio e com bom grau de compreensão se forem utilizadas metodologias e linguagens adequadas com seu contexto escolar e social. Desta forma, as oficinas são planejadas com base em atividades desplugadas [Bell et al. 2011] e levando em consideração as diretrizes para ensino de computação na educação básica sugeridas pela $\mathrm{SBC}^{6}$.

As ações do projeto têm como público principal professoras e professores da Educação Básica de modo que essas(es) professoras(es) possam replicar os conhecimentos construídos durante as oficinas ofertadas pelo TIChers. Esses conhecimentos vão desde o esclarecimento sobre conceito de pensamento computacional, até conteúdos de áreas específicas da computação. A ideia não é formar professoras(es) em Computação, mas sim formá-las(os) a ponto de compreender como

\footnotetext{
${ }^{5}$ www.meninas.sbc.org.br

${ }^{6} \mathrm{http}$ //sbc.org.br/documentos-da-sbc/summary/203-educacao-basica/1220-bncc-em-itinerarioinformativo-computacao-2
} 
as ferramentas construídas com base na computação podem impactar a sociedade e assim atrair suas alunas e seus alunos para contribuir com esse processo de transformação. Especialmente falando sobre as meninas que são alunas dessas(es) professoras(es), serão positivamente impactadas pelo projeto uma vez que a representatividade será um fator ponderado.

São realizadas oficinas mensais com grupos de docentes da Educação Básica de Curitiba. As turmas tem entre 15 a 30 docentes. A indicação e seleção de docentes é feita pela Secretaria Municipal de Educação. As oficinas acontecem nos dias específicos de formação continuada ${ }^{7}$, geralmente segundas e sextas-feiras. Cada oficina tem duração de 4 horas.

\section{Resultados preliminares}

As primeiras oficinas do TIChers foram realizadas em agosto de 2019. Até o momento duas oficinas foram realizadas. Cada oficina foi realizada com três turmas distintas, contemplando 90 docentes da Educação Básica. Uma das oficinas apresenta conceitos de Banco de Dados, com base no trabalho de [Berardi et al. 2019] e a outra faz uma adaptação na proposta de [Rodrigues et al. 2019] que apresenta conceitos de Pensamento Computacional a partir da história de Ada Lovelace.

Durante as oficinas de aprendizado cinestésico de banco de dados foi possível notar o encantamento provocado pela atividade desplugada para a área de computação. As professoras externaram a dificuldade de realizar atividades que dependam de computadores pela falta de recursos e atividades desplugadas facilitam. Outro ponto possível de perceber foi que raramente elas haviam tido uma experiência com oficinas de computação que não falassem especificamente sobre alguma linguagem de programação, e mesmo assim elas conseguiram captar a importância de trabalhar assuntos de computação em sala de aula. $\mathrm{Na}$ oficina foram trabalhados conceitos de banco de dados e benefícios de se utilizar esse tipo de conhecimento, para soluções em diversas áreas como saúde, educação. Ao final da oficina as professoras questionaram por estudos que mostrassem como conectar tais conhecimentos com o currículo base. Isso mostra a demanda por formação em diferentes conteúdos da computação para essas professoras e assim possibilitarem uma formação continuada sobre as diferentes áreas da computação.

A oficina que apresenta conceitos do Pensamento Computacional através de atividades articuladas com a história de vida de Ada Lovelace promove o engajamento de docentes de diversas áreas. Docentes de Língua Portuguesa vislumbram atividades para as suas aulas, assim como docentes de História e Matemática. A gestão do governo municipal atual tem uma pauta de tecnologia muito forte. Isto também contribui para o envolvimento de docentes que atuam com projetos de robótica nas escolas. O projeto do cavalo mecânico voador de Ada Lovelace, por exemplo, inspira novas ideias a serem colocadas em prática por este grupo de docentes.

A diversidade de docentes, considerando-se a formação e a área específica de atuação em sala de aula, traz riqueza para o debate durante as oficinas. Em todas as

\footnotetext{
${ }^{7}$ Docentes da Educação Básica de Curitiba tem um dia na semana dedicado à sua formação continuada.
} 
atividades, estimula-se cada participante a refletir sobre como o conteúdo apresentado poderia ser aplicado no contexto de suas aulas com estudantes da Educação Básica.

\section{Considerações finais}

O cenário da pandemia provocada pelo COVID19 já causou impactos no projeto. As oficinas agendadas para maio foram canceladas. A coordenação do projeto apresentou a possibilidade de uma conversa online com o grupo de docentes da Educação Básica. Entretanto, a preparação das aulas que estão sendo ministradas de maneira remota para estudantes da Educação Básica Municipal está gerando uma sobrecarga de trabalho para as docentes do município. Desta forma, ainda não foi possível definir a nova agenda de oficinas do TIChers.

Por outro lado, a pandemia também evidencia a necessidade de compreensão do funcionamento dos sistemas de informação, seja para aulas à distância, para o comércio eletrônico, para receber ajuda financeira por parte do governo ou simplesmente para fins de entretenimento. Desta forma, a necessidade por conscientização e formação sobre conceitos diversos da Computação e o reconhecimento da importância de profissionais da área fortalece a importância de projetos como o descrito neste artigo, bem como os demais projetos parceiros do PMD.

\section{Referências}

Bell, T., Witten, I., e Fellows, M. (2011) "Computer Science Unplugged - Ensinando Ciência da Computação sem o uso do Computador." Tradução de Luciano Porto Barreto. Disponível em: http://csunplugged.org/. Acesso em 12/05/2020

Berardi, R. C. G., Kozievitch, N., Bim, S. A. e Auceli, P. (2019) "Oficina de Banco de Dados com Aprendizado Cinestésico para Meninas do Ensino Médio". In Anais do Workshop de Informática na Escola (Vol. 25, No. 1, p. 345).

Graeff, R. V., Patias, N. D. (2018) "Orientação profissional em uma escola privada: experiência de estágio." Revista de Psicologia da IMED, Passo Fundo, v.10, n. 1, p. 175-186, ISSN 2175-5027.

Maciel, C., Bim, S. A., e Figueiredo, K. da S. (2018). "Digital girls program: disseminating computer science to girls in Brazil." In Proceedings of the 1st International Workshop on Gender Equality in Software Engineering, pages 29-32.

Ribeiro, K. da S. F. M. (2020b) "Gênero, Tecnologia e Formação: o desenvolvimento da carreira de estudantes do ensino médio integrado em Informática." Tese de Doutorado. Programa de Pós-Graduação em Educação. Instituto de Educação. Universidade Federal do Mato Grosso. Cuiabá - MT.

Ribeirto, L. (2019). Ensino de computação na Educação Básica - as diretrizes da SBC. Computação Brasil - Revista da Sociedade Brasileira de Computação, Porto Alegre, n.41, p. 6-9.

Rodrigues, R. F., Bim, S. A., Maciel, C., Pires, F. G., Lobo, M. M., Pessoa, L., Rangel, J., Pereira, K.S., Bernardo, J.R. "Circuit of Computer Science Unplugged activities based on the life of Ada Lovelace.” In: XI LAWCC at CLEI 2019, 2019, Panamá. Proceedings LAWCC, 2019.

Siqueira, I. C. P. (2019) "Por que precisamos de Computação na Educação Básica? Computação Brasil - Revista da Sociedade Brasileira de Computação, Porto Alegre, n. 41, p. 19 - 21. 